\begin{tabular}{|c|c|c|c|}
\hline $\begin{array}{l}\text { Case Reports in } \\
\text { Cicis: }\end{array}$ & $\begin{array}{l}\text { Case Rep Oncol 2010;3:315-325 } \\
\text { DOI: 10.1159/000320623 }\end{array}$ & \begin{tabular}{|l} 
Published online: \\
September 9, 2010
\end{tabular} & \begin{tabular}{|l} 
() 2010 S. Karger AG, Basel \\
ISSN 1662-6575 \\
www.karger.com/cro
\end{tabular} \\
\hline
\end{tabular}

\title{
An Unusual Case of Peritoneal Carcinomatosis
}

\author{
Stijn Hillewaere ${ }^{\mathrm{a}}$ Linde Stessens $^{\mathrm{b}} \quad$ Kurt Van der Speeten $^{\mathrm{a}}$ \\ Departments of aSurgical Oncology and 'PPathology, Ziekenhuis Oost-Limburg, \\ Genk, Belgium
}

\section{Key Words}

Peritoneal carcinomatosis - Cytoreductive surgery · Hyperthermic intraperitoneal perioperative chemotherapy · Paraganglioma

\begin{abstract}
The peritoneal surface remains an important failure site for patients with gastrointestinal and gynecologic malignancies. In the past, oncologists regarded peritoneal carcinomatosis as an incurable component of an intra-abdominal malignancy. During the last two decades, novel therapeutic approaches have emerged for peritoneal carcinomatosis patients. We report the first case of peritoneal carcinomatosis emerging from an extra-adrenal, intra-abdominal paraganglioma. This 49-year-old male was treated with cytoreductive surgery and hyperthermic intraperitoneal perioperative chemotherapy. Paragangliomas are rare tumors of neural crest-derived chromaffin cells and can originate either from the sympathetic or from the parasympathetic ganglia. It has been estimated that as many as $10 \%$ of the paragangliomas arise outside the adrenal glands. This case represents an unreported presentation of paraganglioma. Two possible origins of this malignancy, and the applied therapy, are discussed. We report the feasibility of cytoreductive surgery plus hyperthermic intraperitoneal perioperative chemotherapy in the treatment of this malignancy.
\end{abstract}

\section{Introduction}

The peritoneal surface remains an important failure site for patients with gastrointestinal and gynecologic malignancies $[1,2]$. In the past, oncologists assumed that peritoneal carcinomatosis (PC) was equal to distant metastases and as such they regarded it as an incurable component of the intra-abdominal malignancy [3]. During the last two decades, novel therapeutic approaches have emerged for PC patients. Those treatments are based on a revised hypothesis that considers $\mathrm{PC}$ as a local-regional disease warranting a local-regional therapeutic approach [4]. An aggressive surgical approach combining visceral resections and peritonectomy procedures should address the macroscopic disease, whereas perioperative [intraperitoneal and/or intravenous (i.v.)] chemotherapy is aimed at residual microscopic disease. In 1980, Spratt et al. [5] reported the use of heated 
triethylenethiophosphoramide in a patient with pseudomyxoma peritonei for the first time. Since then, one randomized trial and several phase II studies have explored the perioperative intraperitoneal route of drug delivery, with promising results [6-10].

Paragangliomas are rare tumors of neural crest-derived chromaffin cells and can originate either from the sympathetic or from the parasympathetic ganglia [11]. These tumors represent $10-18 \%$ of all chromaffin tissue-related tumors [11, 12]. It has been estimated that as many as $10 \%$ of the paragangliomas arise outside the adrenal glands [13].

We report the first case of PC due to paraganglioma and the application of cytoreductive surgery and intraperitoneal chemotherapy in this patient.

\section{Case Report}

\section{Presentation}

A 49-year-old male presented with diffuse abdominal pain requiring minor analgesia. Obstructed defecation was present for five months. Appetite was normal and no nausea, vomiting or weight loss were reported. The clinical examination was within normal limits. Biochemistry revealed a hemoglobin level of $12.7 \mathrm{~g} / \mathrm{dl}$ (reference range 13.1-17.2 g/dl) and a CRP level of $6.8 \mathrm{mg} / \mathrm{dl}$ (reference range $<0.5$ $\mathrm{mg} / \mathrm{dl})$. Carcinoembryonic antigen level was within normal limits $(<0.2 \mathrm{ng} / \mathrm{ml}$; reference range $0-5$ $\mathrm{ng} / \mathrm{ml})$.

\section{Diagnostic Workup}

A plane X-ray of the abdomen described no abnormalities. Ultrasonography of the abdomen revealed a $17 \times 19 \mathrm{~cm}$ semisolid tumor mass with cystic components caudally to the right lobe of the liver. The mass had a very irregular border and an inhomogeneous content. A subsequent computed tomography $(\mathrm{CT})$ confirmed the $15 \times 11 \times 19 \mathrm{~cm}$ tumor mass with suggested signs of malignancy (tumor size, signs of necrosis, peritoneal metastasis) (fig. 1). There was evidence of peritoneal involvement and omental extension. The CT images also depicted a similar tumor nodule of $5 \mathrm{~cm}$ in diameter, localized in the cavum douglasi. Subsequent gastroscopy and left colonoscopy were normal. Positron emission tomography (PET) scan showed the abovementioned abdominal localizations.

\section{Treatment}

The patient underwent an explorative laparotomy and subsequent cytoreductive surgery, followed by HIPEC. First, the biggest peritoneal tumor mass was resected en bloc with the omentum, pancreatic capsule and a part of the pancreatic head. A right-sided diaphragmatic peritonectomy (according to Vazquez and Sugarbaker [14]) was carried out. The ligamentum umbilicale was excised up to the level of the left portal vein and a total peritonectomy of Morisson's pouch was performed. A few peritoneal tumor nodules on the liver capsule were resected, followed by a partial resection of the peritoneum of the left diaphragma. Due to a big fixed nodule on the spleen, a splenectomy was done. Thereafter, a bursectomy of the bursa omentalis minor with excision of the omentum minus was completed. A few nodules $(1$ to $3 \mathrm{~mm}$ ) on the mesentery of the small bowel were resected, but the bowel itself appeared normal. On the mesentery of the colon transversum we also resected some tumor nodules. The colon itself turned out to be normal, except in the cavum douglasi, which was obliterated by tumor tissue. We decided to perform an en bloc anterior resection and pelvic peritonectomy. Eventually, a CC-0-CC-1 cytoreduction was achieved.

Subsequent hyperthermic intraperitoneal perioperative chemotherapy (HIPEC) (open abdominal technique [15]) with cisplatinum $\left(50 \mathrm{mg} / \mathrm{m}^{2}\right.$ for a total dose of $\left.110 \mathrm{mg}\right)$ and doxorubicin $\left(15 \mathrm{mg} / \mathrm{m}^{2}\right.$ for a total dose of $33 \mathrm{mg}$ ) was initiated at $41.5^{\circ} \mathrm{C}$ for $90 \mathrm{~min}$. A 2 liter $/ \mathrm{m}^{2}$ isotonic icodextrin carrier solution 
(1.5\%) was used. The i.v. component of the bidirectional intraoperative chemotherapy consisted of 5fluorouracil $880 \mathrm{mg}\left(400 \mathrm{mg} / \mathrm{m}^{2}\right)$ i.v. and leucovorin $44 \mathrm{mg}\left(20 \mathrm{mg} / \mathrm{m}^{2}\right)$, both administered via separate i.v. accesses. The patient tolerated the procedure well. The diuresis was kept above $2 \mathrm{ml} / \mathrm{kg} / \mathrm{h}$. The hyperglycemia due to the carrier fluid was countered with an insulin drip [16]. The total duration of the procedure was $14 \mathrm{~h}$ and $20 \mathrm{~min}$. The postoperative stay was without complications.

After nine months, no evidence of recurrent disease was detected.

Pathology

At macroscopy, the largest nodule showed extensive hemorrhage and some cyst-like areas (ig. 2 ). Histologically, the tumor had a mixture of spindle-shaped and syncytial growth pattern. Abundant vascular structures were present. The nodular groups of cells were divided by tiny fibrovascular axes, thus resembling a neuroendocrine tumor. The cells were monomorphic with an abundant eosinophilic or clear cytoplasm. Mitotic activity was mild.

On immunohistochemical stainings, tumor cells were positive for synaptophysin (ig. 3 ) and vimentin. Few cells were positive for desmin. Staining for keratin, EMA, CK7, neurofilament, chromogranin, S-100, actin, CD34 and CD117 was negative. The S-100 staining was positive in some sustentacular cells. Proliferation marker Ki-67 was positive in 3\% of tumor cells. Based on the morphological appearance and the immunohistochemical findings, an abdominal extra-adrenal paraganglioma was the most likely diagnosis.

Other resected nodules (table 1) harbored metastases of the paraganglioma.

\section{Discussion}

\section{A New Paradigm in the Treatment of PC}

The surface of the abdomen and pelvis are important anatomic sites for the dissemination of gastrointestinal and gynecologic malignancies. Tumor cells may exfoliate from the primary tumor into the peritoneal cavity preoperatively due to transserosal growth [17]. Alternatively, at the time of surgery, tumor cells can be dispersed from transected lymph or blood vessels, or by manipulation of the primary tumor. Once malignant cells are free inside the peritoneal cavity, they become trapped at sites of trauma where fibrin accumulations and blood clots will secure them and enhance their growth $[18,19]$. Eventually, this may result in the development of clinical PC. The reported incidence in the literature varies widely. For example, in a review of 2,756 patients by Jayne et al. [2], the incidence of $\mathrm{PC}$ at the time of initial surgery was reported to be $7.7 \%$. A review of colonic cancer patients who had recurrences suggest that peritoneal seeding occurred in $25 \%$ to $35 \%$ of patients [20].

In the past, $\mathrm{PC}$ has long been considered a terminal disease stage with no curative treatment options. Chu et al. [3] were the first to investigate the impact of PC upon survival. In 100 patients with biopsy-proven PC, they reported a mean survival of 8.5 months in colorectal cancer patients, 2.4 months in pancreatic cancer patients and 2.2 months in gastric cancer patients. The European prospective multicenter trial EVOCAPE 1 (Evolution of PC 1) reported remarkably similar results in nongynecologic malignancy patients with PC who received 5-fluorouracil-based systemic chemotherapy [1]. In 2002, Jayne et al. [2] reported a median survival of 7 months in colorectal cancer patients who had synchronous peritoneal implants. Some reliable data on this topic came from the 
control arm of the phase III trial by Verwaal et al. [6]. A recent update of this trial revealed a median disease-specific survival of 12.6 months in patients with PC from colorectal cancer who received 5-fluorouracil-leucovorin-based systemic chemotherapy [7]. More recent systemic chemotherapy protocols based on the use of oxaliplatin, irinotecan and biologic agents have improved survival in colorectal cancer patients with PC. Elias et al. [8] reported a 23.9-months median survival in 48 colorectal cancer patients with small-volume carcinomatosis who were treated with systemic chemotherapy containing oxaliplatin or irinotecan. It is important to mention that no long-time survivors are reported in these series.

During the last two decades, novel therapeutic approaches to PC have emerged, combining cytoreductive surgery and perioperative (intraperitoneal and/or i.v.) chemotherapy. The perioperative intraperitoneal chemotherapy includes HIPEC and/or early postoperative intraperitoneal chemotherapy (EPIC). Elias et al. [21] first reported the clinical use of intraoperative i.v. 5-fluorouracil and leucovorin in conjunction with oxaliplatin-based HIPEC in 2002. Most recent protocols advocate this bidirectional (simultaneous intraperitoneal and i.v. chemotherapy) intraoperative chemohyperthermy.

Spratt et al. [5] reported, in 1980, the use of heated triethylenethiophosphoramide in a patient with pseudomyxoma peritonei for the first time. Since then one randomized controlled trial and several phase II studies have explored the perioperative intraperitoneal route of drug delivery. In an update on their phase III trial, Verwaal et al. [7] reported a 45\% 5-year survival in colorectal PC patients receiving optimal cytoreduction and HIPEC with mitomycin C followed by systemic chemotherapy. Elias et al. recently analyzed the results of combined cytoreductive surgery and perioperative chemotherapy in 1,290 patients with PC due to a variety of primary malignancies [22]. After 5 years, 37\% of these patients were still alive. These encouraging clinical results are in strong contrast with historical control groups and patients treated with systemic chemotherapy alone and there is no doubt that the clinical evidence in the medical literature supporting the combined approach of cytoreductive surgery and perioperative intraperitoneal chemotherapy is growing.

\section{The Paraganglioma}

Paragangliomas are rare tumors of neural crest-derived chromaffin cells and can originate either from the sympathetic or from the parasympathetic ganglia [11] (table 2). Approximately $25 \%$ of sympathetic-derived and $50 \%$ of parasympathetic-derived paragangliomas are inheritable [12]. The younger the patients are at the time of diagnosis, the more likely they are to have familial disease $[23,24]$.

The modes of presentation of paraganglioma may be divided into mass effect, incidental discovery and excess catecholamine production (classically with headache, palpitation, sweating, and episodic hypertension). In familial cases, genetic screening of family members is another common route for discovery [12]. Most head and neck paragangliomas are nonsecreting tumors [25].

Unlike pheochromocytomas, which have been classically described as having a 10\% malignancy rate, intra-abdominal paragangliomas tend to be the most aggressive sympathetic-derived paragangliomas [12]. The incidence of malignancy ranges from 14\% 
to as high as 50\%, depending on series [26]. These malignant tumors tend to spread hematogenously, lymphatically, and through local invasion [12]. Unfortunately, even final pathology does not reliably predict biological behavior [12].

\section{Peritoneal Presentation of Extra-Adrenal Paraganglioma}

This case represents an unreported presentation of a paraganglioma. This extraadrenal, intra-abdominal paraganglioma could be the metastasis of a regressed primary tumor or it could be a primary, peritoneal presentation of an extra-adrenal paraganglioma. The first would be a case of cancer of unknown primary (CUP) origin. CUP is defined as biopsy-proven metastasis from a malignancy in the absence of an identifiable primary site after a complete clinical workup [27]. This entity is classified into several histological types and a paraganglioma would be a case of a neuroendocrine CUP. Prasad et al. [28] describe a series of 59 patients with documented neuroendocrine tumors and unknown primary. Using $68 \mathrm{Ga}$-labeled (1,4,7,10-tetraazacyclododecane$\mathrm{N}, \mathrm{N}^{\prime}, \mathrm{N}^{\prime \prime}, \mathrm{N}^{\prime \prime \prime}$-tetraacetic acid)-1-NaI3-octreotide (68Ga-DOTA-NOC) PET/CT, the site of the primary was localized in 35 patients, one of which had a primary paraganglioma. The other possibility of a primary extra-adrenal paraganglioma would be derived from chromaffin cells in the peritoneum. Based on anatomical distribution, extra-adrenal paragangliomas of the abdomen are divided into three major groups [28] (table 2). Freedman and Goldman [29] reported a case of a normal paraganglion in the mesosigmoid and emphasized the potential for a neoplastic paraganglioma to develop in this area and in other unusual locations. Sporadic cases of paragangliomas arising in locations outside the distribution of the autonomic nervous system, where normal paraganglionic tissue had not yet been characterized, have been described [28]. These can be explained by the dispersed migratory property of the neural crest [30]. Kudoh et al. [30] reported in 2005 what was, to their knowledge, only the seventh case of paraganglioma arising in the mesentery. They assumed that the mesenteric paraganglioma was derived from the paraganglionic cells by vertebral migration from the root of the superior mesentery artery. Based on these findings and on the pathologic characteristics of the tumor we present, we believed our patient to have a primary extraadrenal paraganglioma.

Due to the unknown origin of the tumor mass before therapy, questions could arise about the rationale of the therapeutic approach. Based on all the examinations performed, a sarcoma was the most likely origin. The first step in therapy was cytoreduction because surgical resection is the treatment of choice for sarcoma [31,32] and investigations revealed this was feasible. With the HIPEC containing cisplatin and doxorubicin as intraperitoneal components, we applied a chemotherapy regimen with cytotoxic effect against a wide variety of malignancies. In fact, among the drugs used so far for intraperitoneal chemotherapy, the combination of cisplatin and doxorubicin appears to be one of the most effective available regimens with acceptable local-regional toxicity [33]. On the other hand, doxorubicin is one of the most active antineoplastic drugs currently available against sarcoma [34] and some studies demonstrated in preclinical models that doxorubicin activity is enhanced by the addition of cisplatin and/or hyperthermia [35]. In order to fine-tune the intraoperative adjuvant therapy, an option could have been to use the intraoperative frozen-section examination, but the techniques used for the evaluation 
of a sarcoma are immunohistochemistry and molecular genetic and cytogenetic investigation [36], so frozen-section examination would be unreliable.

Knowing the results of the pathologic examination, other therapeutic options can now be suggested, although it is accepted that the mainstay of therapy for primary paraganglioma is complete surgical resection. For malignant, metastatic or unresecable paragangliomas, ${ }^{131}$ I-metaiodobenzylguanidine (MIBG) is a well-documented treatment [12]. The norepinephrine transporter (NET) plays a key role in this treatment modality [37]. It is expressed on chromaffin cells of extra-adrenal paragangliomas and is used to incorporate ${ }^{131} \mathrm{I}-\mathrm{MIBG}$ in tumor cells. In this way it can achieve significant therapeutic responses in malignant pheochromocytoma without biochemical toxicity and with only mild radiotoxicity $[38,39]$. The use of traditional chemotherapeutic agents such as cisplatinum or doxorubicin was investigated to increase NET functional activity [37] and thus to augment the effectiveness of ${ }^{131}$ I-MIBG therapy. For neuroblastoma, Meco et al. [40] suggested that the combination of ${ }^{131}$ I-MIBG and cisplatinum or doxorubicin could selectively increase radiation doses delivered to neuroblastoma cells. However, there are probably intrinsic differences between the pheochromocytoma and neuroblastoma cell lines, as pretreatment of the rat pheochromocytoma PC12 cell line with cisplatinum does not increase the functional activity of the transporter [39]. Only sparse data on the use of chemotherapy against paraganglioma are presented in the literature. In 1988, Averbuch et al. [41] concluded that combination chemotherapy with cyclophosphamide, vincristine, and dacarbazine (CVD) is effective for advanced malignant pheochromocytoma. This chemotherapy regimen was recently confirmed in a review of Adjallé et al. [42]. Chemotherapy should be applied to patients without positive MIBG-scan, with no response to $\left.{ }^{131}\right) \mathrm{I}-\mathrm{MIBG}$ or progression after radionuclide treatment, and especially in cases with a high proliferation index. A number of case reports have been published using the same regimen for malignant paraganglioma [43-45]. A slightly different chemotherapy regimen was proposed in 1995 by Patel et al. [46]. The authors concluded that CVD chemotherapy is active in the treatment of patients with paraganglioma. Although there are thus a few possible chemotherapy regimens to treat inoperable paraganglioma, there is no consensus about them in the literature. Clinical studies indicate, however, that doxorubicin has a possible in vivo effect against paraganglioma.

\section{Role of Cytoreductive Surgery and HIPEC in PC with Paraganglioma Origin}

There is no doubt that cytoreductive surgery is the essential first step in the treatment of PC with paraganglioma origin. Not only the use of HIPEC, but also the specific intraperitoneal and i.v. components of the bidirectional, intraoperative chemotherapy remains uncertain. Phase-II clinical trials are needed to provide more supportive evidence but, due to the rarity of the disease, they are unlikely to happen. This report, together with findings in the literature, suggests a possible role for HIPEC in the treatment of PC with paraganglioma origin.

\section{Conclusion}

This report provides the first case of extra-adrenal, intra-abdominal paraganglioma PC. The optimal treatment of this malignancy has yet to be established. In our experience, 
the combination of cytoreductive surgery and HIPEC is feasible. This treatment resulted in minor morbidity, no mortality and short-term disease-free survival.

Table 1. Other specimens examined, containing all metastases of the big tumor mass

Multiple peritoneal metastases

Omentum

Gall bladder (weight $34 \mathrm{~g}$, length $8 \mathrm{~cm}$ )

Liver metastasis

Metastasis on liver capsule

Peritonectomy of the left diaphragm

Peritonectomy of the right diaphragm

Spleen (weight $290 \mathrm{~g}$ )

Bursa omentalis minor

Omentum minus

Metastasis in the mesocolon transversum

Piece of mesenterium of the small bowel

Right paracolic gutter

Cecal metastases

Resection piece of the anterior resection (length $25 \mathrm{~cm}$ ) with pelvic peritonectomy

Table 2. Origin and anatomic distribution of paragangliomas (neural crest-derived chromaffin cells) $[12,13,26]$

1 Parasympathetic ganglia: almost exclusively in the neck and skull base

2 Sympathetic ganglia:

a Adrenal medulla (pheochromocytoma): $\pm 90 \%$

b Sympathetic paraganglioma (extra-adrenal pheochromocytoma): $\pm 10 \%$ : along the sympathetic chain:

$\begin{array}{lc}\text { Area } & \text { Incidence } \\ \text { Cervical } & 3 \% \\ \text { Intrathoracic } & 12 \% \\ \text { Intra-abdominal } & 85 \% \\ \quad \text { Superior para-aortic } & 45 \% \\ \quad \text { Inferior para-aortic } & 30 \% \\ \quad \text { Urinary bladder } & 10 \%\end{array}$




\begin{tabular}{|c|c|c|c|}
\hline $\begin{array}{l}\text { Case Reports in } \\
\text { Orou:ati }\end{array}$ & $\begin{array}{l}\text { Case Rep Oncol 2010;3:315-325 } \\
\text { DOI: } 10.1159 / 000320623\end{array}$ & $\begin{array}{l}\text { Published online: } \\
\text { September 9, } 2010\end{array}$ & $\begin{array}{l}\text { ( ) } 2010 \text { S. Karger AG, Basel } \\
\text { ISSN 1662-6575 } \\
\text { www.karger.com/cro }\end{array}$ \\
\hline
\end{tabular}
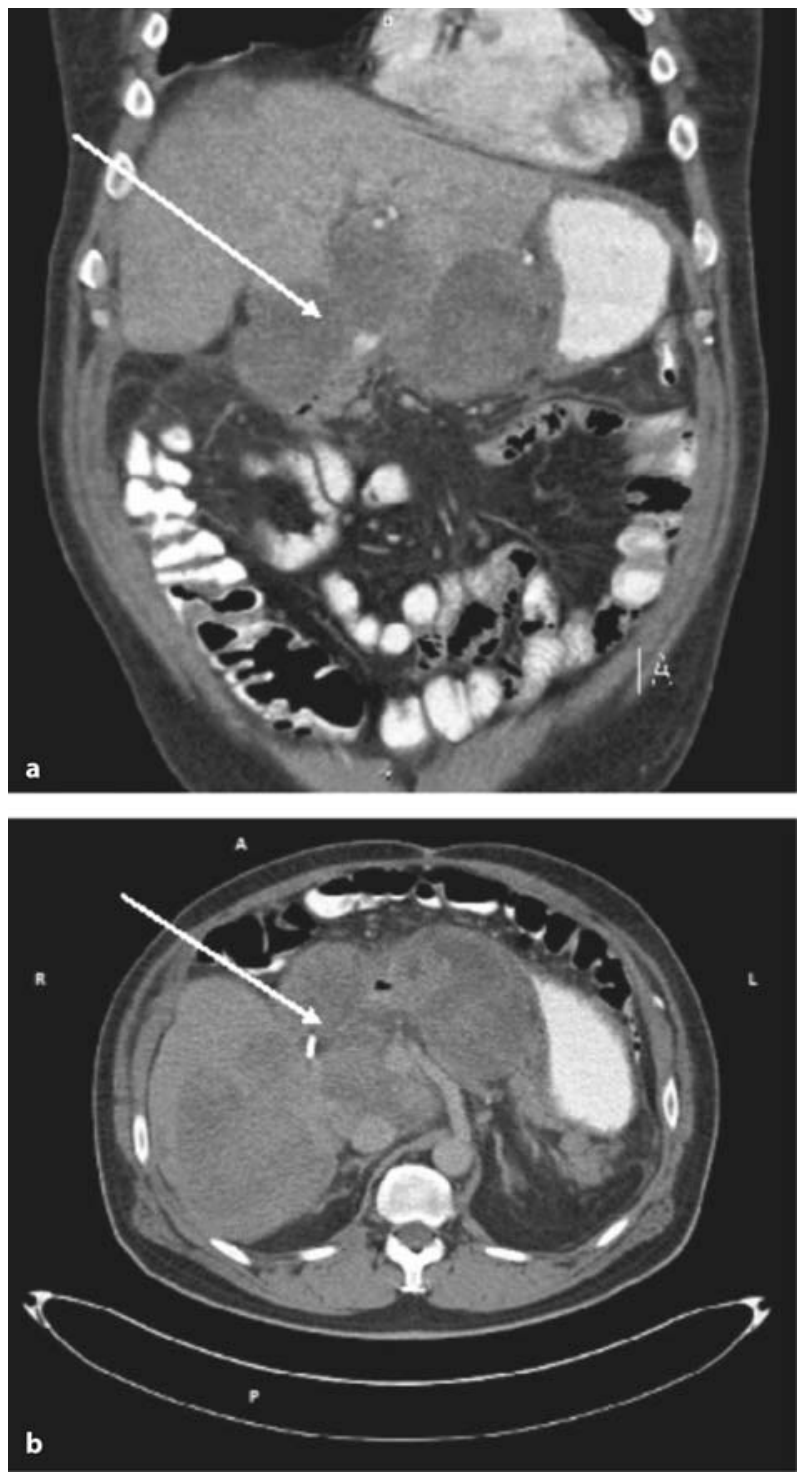

Fig. 1. CT-image. A 49-year-old male presented with diffuse abdominal pain requiring minor analgesia. Obstructed defecation was present for five months. CT-image demonstrated a $15 \times 11 \times 19$ $\mathrm{cm}$ tumor mass with signs of malignancy (tumor size, signs of necrosis, peritoneal metastasis). The mass was localized caudally to the right lobe of the liver. a: Frontal plane. b: Horizontal plane. 


\begin{tabular}{|c|c|c|c|}
\hline $\begin{array}{c}\text { Case Reports in } \\
\text { Oic: }\end{array}$ & $\begin{array}{l}\text { Case Rep Oncol 2010;3:315-325 } \\
\text { DOI: } 10.1159 / 000320623\end{array}$ & $\begin{array}{l}\text { Published online: } \\
\text { September } 9,2010\end{array}$ & $\begin{array}{l}\text { O } 2010 \text { S. Karger AG, Basel } \\
\text { ISSN 1662-6575 } \\
\text { www.karger.com/cro }\end{array}$ \\
\hline
\end{tabular}

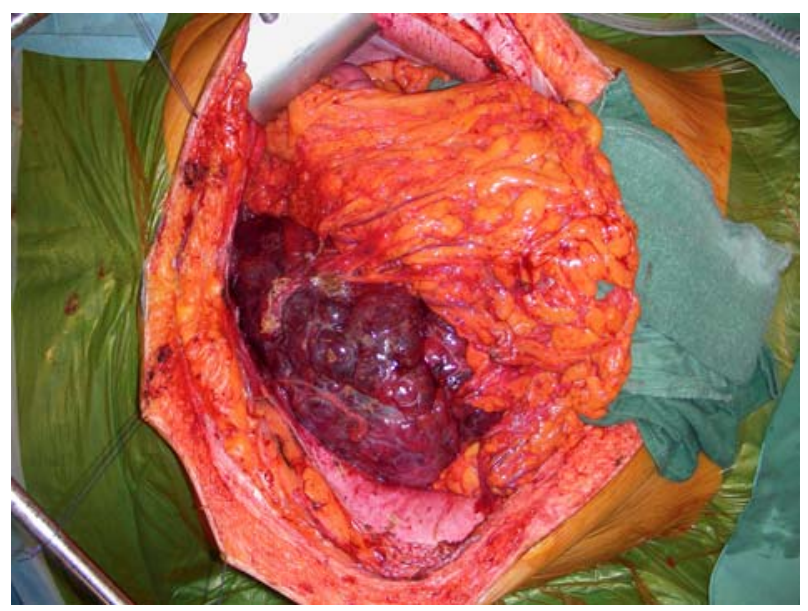

Fig. 2. Macroscopic image. Macroscopic perioperative image of large tumor mass. It is primary localized in the right upper abdominal quadrant and appears hemorrhagic and to some extent cystic (head of patient at the left side).

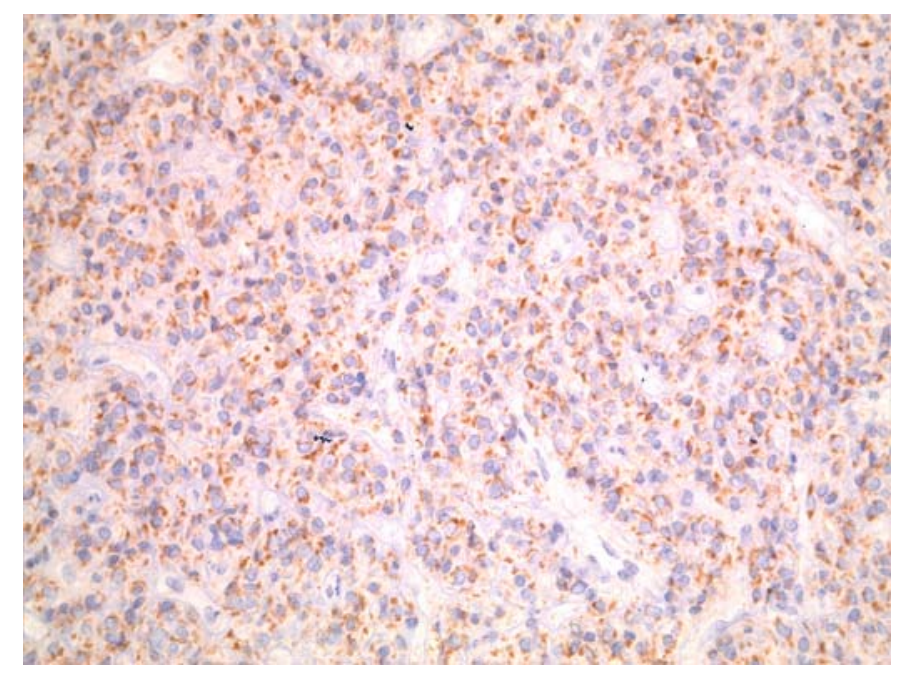

Fig. 3. Microscopic image. Immunostain for synaptophysin shows paranuclear dots on a biopsy taken from the large tumor mass.

\section{References}

1 Sadeghi B, Arvieux C, Glehen O, Beaujard A, Rivoire M, Baulieux J, Fontaumard E, Brachet A, Caillot J, Jean L. Faure J, Porcheron J, Peix J, François Y, Vignal J, Gilly F: Peritoneal carcinomatosis from non-gynecologic malignancies: results of the EVOCAPE 1 multicentric prospective study. Cancer 2000;88:358-363.

-2 Jayne DG, Fook S, Loi C, Seow-Choen F: Peritoneal carcinomatosis from colorectal cancer. Br J Surg 2002;89:1545-1550.

-3 Chu DZ, Lang NP, Thompson C, Osteen PK, Westbrook KC: Peritoneal carcinomatosis in nongynecologic malignancy. A prospective study of prognostic factors. Cancer 1989;63:364-367.

4 Sugarbaker PH: Peritonectomy procedures: Surg Oncol Clin N Am 2003;12:703-727. 
5 Spratt JS, Adcock RA, Muskovin M, Sherrill W, McKeown J: Clinical delivery system for intraperitoneal hyperthermic chemotherapy. Cancer Res 1980;40:256-260.

-6 Verwaal VJ, van Ruth S, de Bree E, van Sloothen GW, van Tinteren H, Boot H, Zoetmulder FA: Randomized trial of cytoreduction and hyperthermic intraperitoneal chemotherapy versus systemic chemotherapy and palliative surgery in patients with peritoneal carcinomatosis of colorectal cancer. J Clin Oncol 2003;21:37373743.

7 Verwaal VJ, Bruin S, Boot H, van Slooten G, van Tinteren H: 8-year follow-up of randomized trial: cytoreduction and hyperthermic intraperitoneal chemotherapy versus systemic chemotherapy in patients with peritoneal carcinomatosis of colorectal cancer. Ann Surg Oncol 2008;15:2426-2432.

$\checkmark 8$ Elias D, Lefevre JH, Chevalier J, Brouquet A, Marchal F, Classe JM, Ferron G, Guilloit JM, Meeus P, Goéré D, Bonastre J: Complete cytoreductive surgery plus intraperitoneal chemohyperthermia with oxaliplatin for peritoneal carcinomatosis of colorectal origin. J Clin Oncol 2009;27:681-685.

-9 Yan TD, Welch L, Black D, Sugarbaker PH: A systematic review on the efficacy of cytoreductive surgery combined with perioperative intraperitoneal chemotherapy for diffuse malignancy peritoneal mesothelioma. Ann Oncol 2007;18:827-834.

10 Yan TD, Black D, Savady R, Sugarbaker PH: A systematic review on the efficacy of cytoreductive surgery and perioperative intraperitoneal chemotherapy for pseudomyxoma peritonei. Ann Surg Oncol 2007:14:484-492.

11 Young WF Jr: Paragangliomas: clinical overview. Ann NY Acad Sci 2006;1073:21-29.

12 Lee JA, Duh Q-Y: Sporadic paraganglioma. World J Surg 2008;32:683-687.

13 Somasundar P, Krouse R, Hostetter R, Vaughan R, Covey T: Paragangliomas - a decade of clinical experience. J Surg Oncol 2000;74:286-290.

14 Vazquez Vde L, Sugarbaker PH: Total anterior parietal peritonectomy. J Surg Oncol 2003;83:261-263.

15 Glehen O, Cotte E, Kusamura S, Deraco M, Baratti D, Passot G, Beaujard AC, Noel GF: Hyperthermic intraperitoneal chemotherapy: nomenclature and modalities of perfusion. J Surg Oncol 2008;98:242-246.

16 De Somer F, Ceelen W, Delanghe J, De Smet D, Vanackere M, Pattyn P, Mortier E: Severe hyponatremia, hyperglycemia, and hyperlactatemia are associated with intraoperative hyperthermic intraperitoneal chemoperfusion with oxaliplatin. Perit Dial Int 2008;28:61-66.

17 Sheperd NA, Baxter KJ, Love SB: The prognostic importance of peritoneal involvement in colonic cancer: a prospective evaluation. Gastroenterology 1997;112:1096-1102.

-18 Sugarbaker PH: Successful management of microscopic residual disease in large bowel cancer. Cancer Chemother Pharmacol 1999;43(suppl):S15-S25.

19 Oosterling SJ, van der Bij GJ, van Egmond M, van der Sijp JR: Surgical trauma and peritoneal recurrence of colorectal carcinoma. Eur J Surg Oncol 2005;31:29-37.

20 Brodsky JT, Cohen AM: Peritoneal carcinomatosis from colorectal cancer. Br J Surg 1991;89:723-727.

-21 Elias D, Bonnay M, Puizillou JM, Antoun S, Demirdjian S, El OA, Pignon JP, Drouard-Troalen L, Ouellet JF, Ducreux M: Heated intra-operative intraperitoneal oxaliplatin after complete resection of peritoneal carcinomatosis: pharmacokinetics and tissue distribution. Ann Oncol 2002;13:267-272.

22 Elias C, Glehen O, Gilly F: Carcinose péritonéales d'origine digestive et primitive. Rapport du 110ème congrès de l'AFC. Arnette, Wolters Kluwer France, 2008.

-23 Amar L, Bertherat J, Baudin E, Ajzenberg C, Bressac-de Paillerets B, Chabre O, Chamontin B, Delemer B, Giraud S, Murat A, Niccoli-Sire P, Richard S, Rohmer V, Sadoul JL, Strompf L, Schlumberger M, Bertagna X, Plouin PF, Jeunemaitre X, Gimenez-Roqueplo AP: Genetic testing in pheochromocytoma or functional paraganglioma. J Clin Oncol 2005;23:8812-8818.

-24 Neumann HP, Bausch B, McWhinney SR, Bender BU, Gimm O, Franke G, Schipper J, Klisch J, Altehoefer C, Zerres K, Januszewicz A, Eng C, Smith WM, Munk R, Manz T, Glaesker S, Apel TW, Treier M, Reineke M, Walz MK, Hoang-Vu C, Brauckhoff M, Klein-Franke A, Klose P, Schmidt H, Maier-Woelfle M, Peçzkowska M, Szmigielski C, Eng C; Freiburg-Warsaw-Columbus Pheochromocytoma Study Group: Germline mutations in nonsyndromic pheochromocytoma. N Engl J Med 2002;346:1459-1466.

25 Plouin PF, Gimenez-Roqueplo AP: Pheochromocytomas and secreting paragangliomas. Orphanet J Rare Dis 2006;1:49.

26 Lack EE: Tumors of the adrenal glands and extraadrenal paraganlia; in Rosai J, Sobin LH (eds): AFIP Atlas of Tumor Pathology Series 4. Washington DC, American Registry of Pathology, 2007, fascicle 8, pp 288-297.

27 Krämer A, Gattenlöhner S, Neben K: CUP syndrome: molecular pathogenesis and biology. Pathologe 2009;30:117-124.

28 Prasad V, Ambrosini V, Hommann M, Hoersch D, Fanti S, Baum RP: Detection of unknown primary neuroendocrine tumours (CUP-NET) using 68Ga-DOTA-NOC receptor PET/CT. Eur J Nucl Med Mol Imaging 2010;37:67-77. 
29 Freedman SR, Goldman RL: Normal paraganglion in the mesosigmoid. Hum Pathol 1981;12:1037-1038.

- 30 Kudoh A, Tokuhisa Y, Morita K, Hiraki S, Fukuda S, Eguchi N, Iwata T: Mesenteric paraganglioma: report of a case. Surg Today 2005;35:594-597.

-31 McGrath PC, Neifeld JP, Lawrence W Jr, Kay S, Horsley JS 3rd, Parker GA: Gastrointestinal sarcomas. Analysis of prognostic factors. Ann Surg 1987;206:706-710.

-32 Liles JS, Tzeng CW, Short JJ, Kulesza P, Heslin MJ: Retroperitoneal and intra-abdominal sarcoma. Curr Probl Surg 2009;46:445-503.

-33 Rossi CR, Mocellin S, Pilati P, Foletto M, Quintieri L, Palatini P, Lise M: Pharmacokinetics of intraperitoneal cisplatin and doxorubicin. Surg Oncol Clin N Am 2003;12:781-794.

-34 Spira AI, Ettinger DS: The use of chemotherapy in soft-tissue sarcomas. Oncologist 2002;7:348-359.

- 35 Rossi CR, Deraco M, De Simone M, Mocellin S, Pilati P, Foletto M, Cavaliere F, Kusamura S, Gronchi A, Lise $\mathrm{M}$ : Hyperthermic intraperitoneal intraoperative chemotherapy after cytoreductive surgery for the treatment of abdominal sarcomatosis: clinical outcome and prognostic factors in 60 consecutive patients. Cancer 2004;100:1943-1950.

36 Thway K: Pathology of soft tissue sarcomas. Clinical Oncology 2009;21:695-705.

-37 Cleary S, Phillips JK: The norepinephrine transporter and pheochromocytoma. Ann NY Acad Sci 2006;1073:263-269.

-38 Shapiro B, Sisson JC, Wieland DM, et al: Radiopharmaceutical therapy of malignant pheochromocytoma with [131I]metaiodobenzylguanidine: results from ten years of experience. J Nucl Biol Med 1991;35:269-276.

-39 Krempf M, Lumbroso J, Mornex R, Brendel AJ, Wemeau JL, Delisle MJ, Aubert B, Carpentier P, Fleury-Goyon MC, Gibold C, et al: Use of m-[131I]iodobenzylguanidine in the treatment of malignant pheochromocytoma. J Clin Endocrinol Metab 1991;72:455-461.

-40 Meco D, Lasorella A, Riccardi A, Servidei T, Mastrangelo R, Riccardi R: Influence of cisplatin and doxorubicin on 125I-meta-iodobenzylguanidine uptake in human neuroblastoma cell lines. Eur J Cancer 1999;35:12271234.

-41 Averbuch SD, Steakley CS, Young RC, Gelmann EP, Goldstein DS, Stull R, Keiser HR: Malignant pheochromocytoma: effective treatment with a combination of cyclophosphamide, vincristine, and dacarbazine. Ann Intern Med 1988;109:267-273.

-42 Adjallé R, Plouin PF, Pacak K, Lehnert H: Treatment of malignant pheochromocytoma. Horm Metab Res 2009;41:687-696.

43 Naoi Y, Tamaki Y, Ooka M, Tsukamoto F, Miyoshi Y, Tanji Y, Taguchi T, Noguchi S: A case of metastatic pheochromocytoma with remarkable response to combination of cyclophosphamide, vincristine and dacarbazine. Gan To Kagaku Ryoho 2003;30:145-149.

44 Uemura M, Nakagawa M, Mukai M, Kanno N, Nishimura K, Miyoshi S, Yoshida K, Kawano K: A case of extra-adrenal pheochromocytoma presenting with lung metastasis. Hinyokika Kiyo 2004;50:29-32.

-45 Maezawa T, Yonese J, Tsukamoto T, Isii N, Hasegawa Y, Ishikawa Y, Fukui I: Low dose CVD chemotherapy as a tumor dormancy therapy for extra-adrenal malignant pheochromocytoma: a case report. Nippon Hinyokika Gakkai Zasshi 2001;92:593-596.

46 Patel SR, Winchester DJ, Benjamin RS: A 15-year experience with chemotherapy of patients with paraganglioma. Cancer 1995;76:1476-1480. 